
Promoting Progenitor Cell Growth

SUBJECT AREAS:

BIOMATERIALS

MATERIALS CHEMISTRY

MEDICAL RESEARCH

CHEMICAL TOOLS

Received

7 February 2013

Accepted

8 April 2013

Published

23 April 2013

Correspondence and requests for materials should be addressed to

S.W. (wangshu@

iccas.ac.cn) or L.B.L.

(liulibing@iccas.ac.cn) \section{Without Serum}

\author{
Gaomai Yang, Libing Liu, Fengting Lv \& Shu Wang
}

Beijing National Laboratory for Molecular Sciences, Key Laboratory of Organic Solids, Institute of Chemistry, Chinese Academy of Sciences, Beijing 100190, P. R. China.

The discovery of new active biomaterials for promoting progenitor cell growth and differentiation in serum-free medium is still proving more challenging for the clinical treatments of degenerative diseases. In this work, a conjugated polyelectrolyte, polythiophene derivative (PMNT), was discovered to significantly drive the cell cycle progression from $G_{1}$ to $S$ and $G_{2}$ phases and thus efficiently promote the cell growth without the need of serum. Furthermore, the fluorescent characteristic of PMNT makes it simultaneously able to trace its cellular uptake and localization by cell imaging. cDNA microarray study shows that PMNT can greatly regulate genes related to cell growth or differentiation. To the best of our knowledge, this is the first example of cell growth or differentiation promotion by polyelectrolyte material without the need of serum, thereby providing an important demonstration of degenerative biomaterial discovery through polymer design.

r he study of growth and proliferation of stem cells or progenitor cells not only holds great significance in biology and medicine, but also provides new hope for the clinical treatments of degenerative diseases ${ }^{1-3}$. To keep cells alive for longer periods of time and to evaluate growth and proliferation in vitro experiment, a basal medium must be supplemented with serum ${ }^{4}$. Serum is a complex containing a large number of components, such as growth factors, proteins, vitamins, trace elements, and hormones. However, due to collection from the unborn calf, seasonal and continental variations in the serum composition can produce batch-to-batch variations. Furthermore, the use of serum is restricted and controversial due to the risk of immune reaction and cross contamination of viral and other pathogens ${ }^{5}$. Since serum-free and component-controllable medium can overcome these limits, the stimulation using growth factors instead of human serum was performed ${ }^{6-8}$. However, the removal of the components of serum is proving more challenging. Some small molecules that are able to promote cell proliferation or growth have been discovered up to date ${ }^{9-12}$. However, the culture medium of these small molecules must be supplemented with serum. Furthermore, these active small molecules were obtained primarily from high-throughput screening, it is difficult to predict and obtain active compounds by molecular design. The discovery of new active compounds for promoting cell growth and differentiation in serum-free medium still remains more challenging.

Conjugated polymers (CPs) for regenerative medicine applications have aroused great attention benefiting from electrical conductivity tuning of CPs, and CP scaffolds were found to promote muscle and nerve cell growth and differentiation by electrical stimulation ${ }^{13-17}$. In a recent study, cells cultured on the CP hydrogel substrates were shown to adhere and proliferate ${ }^{14}$. In this work, we discovered a conjugated polyelectrolyte, polythiophene derivative (PMNT, see its chemical structure in Figure 1) ${ }^{18,19}$ for efficiently promoting cell growth without serum. We comprehensively studied the effect of growth promotion of PMNT toward MC3T3 cells (primary mouse osteoblasts, widely used as model systems in bone biology) without serum. Flow cytometry study shows PMNT can significantly drive the cell cycle progression from $G_{1}$ to $S$ and $G_{2}$ phases. cDNA microarray study shows that PMNT can regulate genes related to cell growth or differentiation. compared with the reported small molecules that can induce cell growth or differentiation, the fluorescent characteristic of PMNT makes it simultaneously be able to trace its cellular uptake and localization by cell imaging. To the best of our knowledge, this is the first example of cell growth or differentiation promotion by polyelectrolytes without the need of serum, thereby providing an important demonstration of future drug discovery to degenerative diseases through polymer design. 


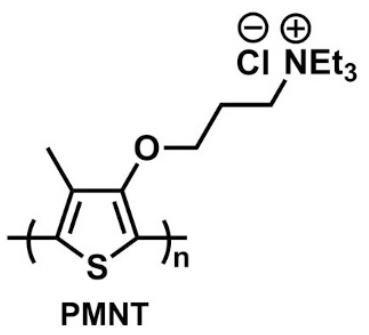

Figure 1 | Chemical structure of PMNT.

\section{Results}

The schematic illustration of cell growth promotion by PMNT is shown in Figure 2. Serum is the most widely used supplement for in vitro cell culture of eukaryotic cells, which supports cell growth and division by providing a broad spectrum of macromolecules, including bovine serum albumin (BSA), attachment factors, nutrients, hormones, and growth factors. Cells cannot undergo normal growth and proliferation in the culture medium without serum. While PMNT-treated cells can grow and proliferate in the culture medium without serum, which means that PMNT can replace the role of serum to some extent and promote the cell growth and proliferation.

To get more insights into the interaction mechanism of PMNT with cells, the location of PMNT in the MC3T3 cells investigated by fluorescence microscopy (FV1000-IX81, Olympus). The fluorescent property of the PMNT (quantum yield: 3\%, maximum emission: $530 \mathrm{~nm})^{18}$ makes it be able to monitor uptake and location in living cells, which eliminates the complicated conjugation steps with additional imaging probes ${ }^{20-22}$. In this experiment, the PMNT was incubated with MC3T3 cells at $37^{\circ} \mathrm{C}$ for $24 \mathrm{~h}$. The medium was removed and the cells were washed with phosphate buffered saline $(1 \times \mathrm{PBS}$, $\mathrm{pH}$ 7.4) for three times before taking images. The cells were also stained by nucleus-specific Hoechst 33258 dye. As shown in Figure 3, PMNT mainly locates in the cytoplasm other than nucleus after it uptakes into the cells, which is proven by the overlap fluorescence images of PMNT and Hoechst 33258.

To test the ability of PMNT for cell growth promotion and exclude the impact of serum, MC3T3 cells were cultured in $\alpha$-MEM medium containing PMNT $(20 \mu \mathrm{M})$ but without serum. The phase contrast images of MC3T3 cells were taken before and after incubation with PMNT for different hours. As shown in Figure 4a, compared with

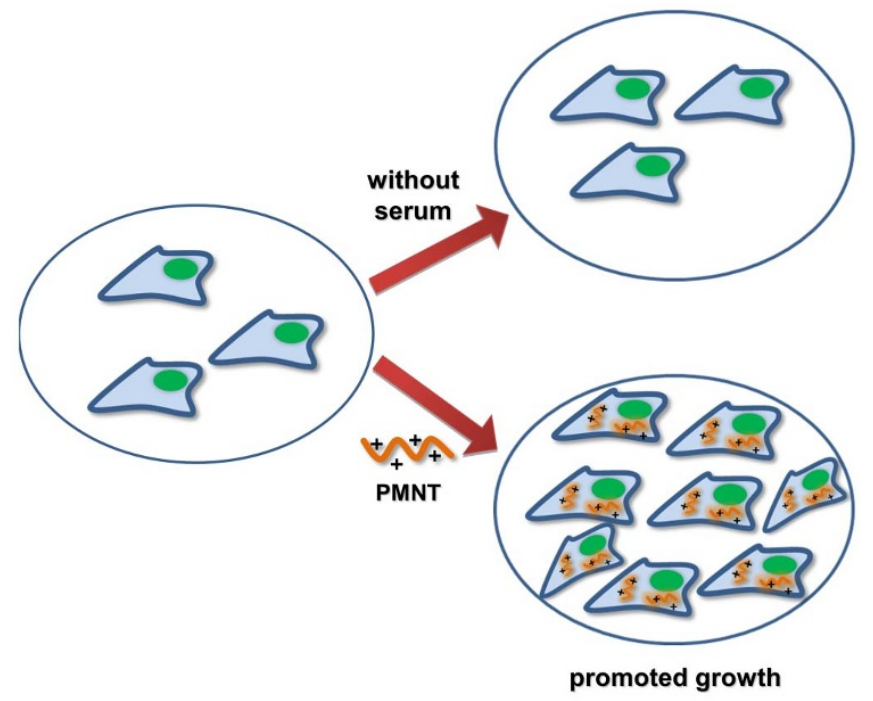

Figure 2 Schematic representation of cell growth promotion by PMNT.
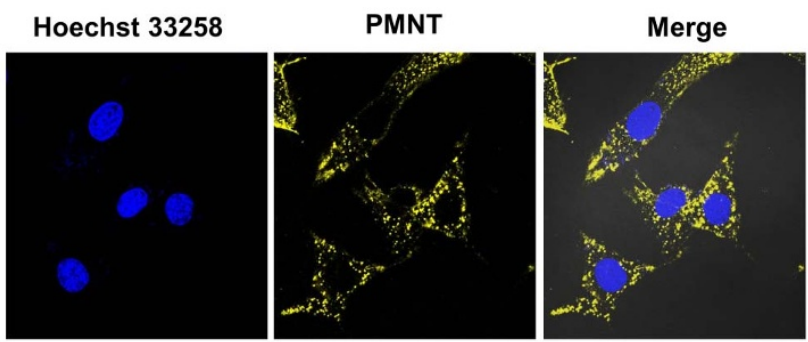

Figure 3 Fluorescence images of MC3T3 cells stained with nuclear dye (Hoechst 33258), PMNT, and the overlapped image. The representative image of PMNT is yellow, the nuclear dye is blue.

the control, the density of MC3T3 cells treated with PMNT was increased in a time-dependent manner. The control experiment exhibits that other positively-charged polyelectrolyte, polyethylenimine (PEI) does not show cell growth promotion (Figure $4 \mathrm{~b}$ ). This difference of cell density was quite obvious after incubating cells with PMNT for $72 \mathrm{~h}$. To further confirm that PMNT promotes the growth of MC3T3 cells, the number of cells treated with and without PMNT was counted. As shown in Figure 4c, no obvious increase of cell growth was observed for the control (without PMNT treatment) throughout the incubation time. However, for the cells treated with PMNT, there was an obvious increase in cell number compared to the control and $160 \%$ increase was observed after $72 \mathrm{~h}$ incubation, which is consistent with the results of phase contrast images. The cytotoxicity of PMNT toward MC3T3 cell line was determined by MTT assay. As shown in Figure 4d, PMNT shows minimal cytotoxicity, even at a high concentration $(200 \mu \mathrm{M})$.

The growth promotion mechanism of PMNT was further studied. Flow cytometry was used for cell cycle analysis of the cells treated with PMNT. As shown in Table 1 and Figure 5, the proportion of cells in G1, S, and G2 phase for PMNT-treated cells and the control (without PMNT treatment) is identical at $4 \mathrm{~h}$. With the increase of incubation time from $4 \mathrm{~h}$ to $16 \mathrm{~h}$, it is noted that for PMNT-treated cells, the proportion of cells in the (S + G2) phase is more than that of the control in a time-dependent manner, which results in a significant increase of proliferative index for PMNT-treated cells. In the following 16-24 h, the proportion of PMNT-treated cells in (S + G2) phase is decreased as the time increases, and the value is similar to that of the control at $24 \mathrm{~h}$ when a complete cycle of mitosis ends. The results indicate that PMNT stimulates the growth of MC3T3 cells by driving their cell cycle progression from G1 to S and G2 phases. The PMNT-treated cells could undergo the normal cell mitosis without being cell cycle arrested in S or G2 phase.

\section{Discussion}

To examine PMNT-regulated genes involved in cell proliferation and cell cycle control, we used cDNA microarray to detect gene transcriptional expression changes associated with PMNT treatment. A typical microarray hybridization image and scatter plot of PMNTregulated changes in gene expression were shown in Figure 6, where control sample label with Cy3 and PMNT-treated sample label with Cy5. As shown in Figure 6a, the red spots indicate that the level of gene expression in PMNT-treated cells is higher than that in the control cells, while the green spots are lower. The relative transcript abundance was expressed as Cy5/Cy3 ratios of signal intensities after background subtraction in each channel. When the ratio of fluorescence intensity of gene labeled Cy5/Cy3 is above ( $\geq$ ) 2, it stands for this gene up-regulation. When the ratio of fluorescence intensity of gene labeled Cy5/Cy3 is below $(\leq)$ ) 0.5 , it stands for this gene downregulation. The red color stands for the up-regulated genes with the $\mathrm{Cy} 5 / \mathrm{Cy} 3$ ratio $\geq 2.0$; the green color stands for the down-regulated genes with the $\mathrm{Cy} 5 / \mathrm{Cy} 3$ ratio $\leq 0.5$; the black color stands for the genes normally expressed. As shown in Figure 6b, PMNT treatment 
a
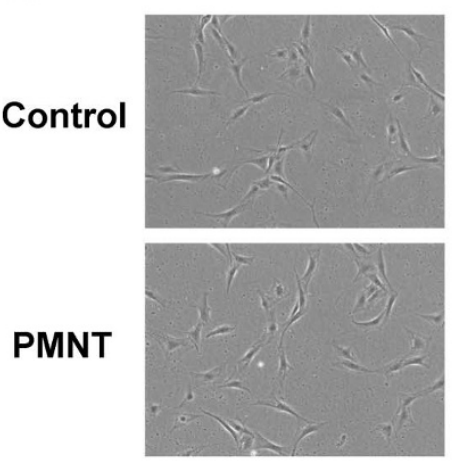

$24 \mathrm{~h}$
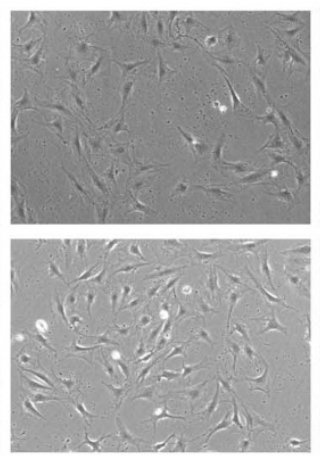

$48 \mathrm{~h}$
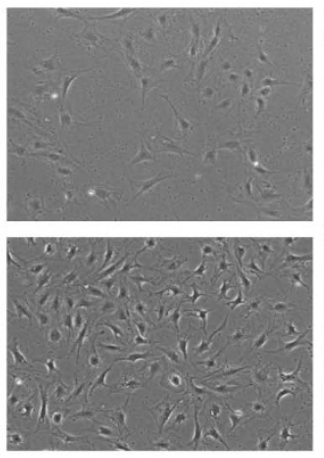

$72 \mathrm{~h}$

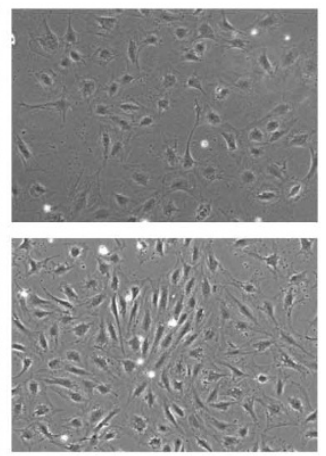

b
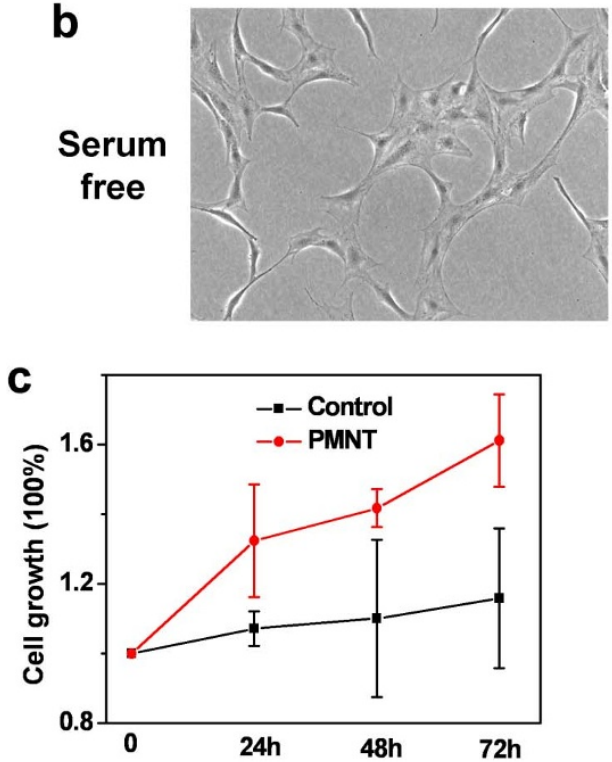

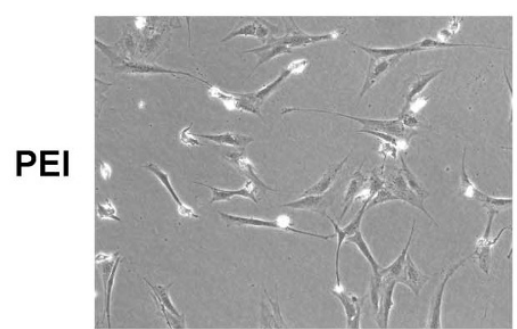

d

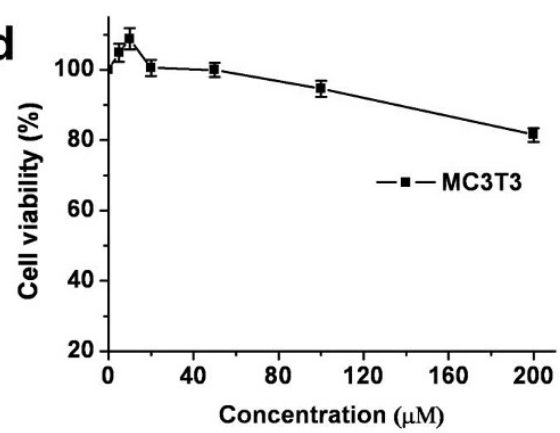

Figure 4| (a) Phase contrast images of MC3T3 cells treated with and without PMNT. [PMNT] $=20 \mu \mathrm{M}$ in repeat unites (RUs). (b) Phase contrast images of MC3T3 cells treated with and without PEI. [PEI] $=2 \mu \mathrm{M}$. (c) Cell number as a function of incubation time for MC3T3 cells treated with and without PMNT. [PMNT] $=20 \mu \mathrm{M}$ in RUs. Error bars correspond to standard deviations from three separate measurements. (d) Cell viability of MC3T3 treated with PMNT using a typical MTT assay. Error bars correspond to standard deviations from three separate measurements.

results in the up-regulation or down-regulation of 704 genes out of the 32256 genes, which represents approximately $2.2 \%$ of the all analyzed genes. Among these 704 genes, 511 of them were upregulated and the other 193 were down-regulated.

The genes in cellular process pathways are especially important to further understand the growth promotion mechanism of PMNT. Expression of eight representative genes mostly related to cell proliferation, apoptosis and the cell cycle are summarized in Table 2, their relative value of the gene expression level for the PMNT-treated group in comparison to that of the control group was shown in Figure 7. Inhibitors of DNA binding/differentiation (Id) family contains four members, Id1-Id4, which are identified as gene products whose function was the negative control of cell differentiation ${ }^{23}$. The
cDNA microarray result of the PMNT sample shows that Id1-Id3 are significantly down-regulated, the $\mathrm{Cy} 5 / \mathrm{Cy} 3$ ratios are $0.07,0.16$, and 0.04 respectively. Because the cell proliferation and differentiation are closely related, thus PMNT has both the abilities to promote cell growth and differentiation. Bone morphogenic proteins (BMPs) and Smad proteins belong to the TGF- $\beta$ superfamily. BMPs can promote proliferation and migration of endothelial cells but inhibit proliferation of human aortic smooth muscle cells ${ }^{24}$. Smad6 is a negative regulator of BMP signaling ${ }^{25}$. The cDNA microarray result of the PMNT sample shows that both BMP-4 and Smad6 are downregulated with the $\mathrm{Cy} 5 / \mathrm{Cy} 3$ ratios of 0.39 and 0.16 , respectively. The result is consistent with the double roles of BMP-4 and the role of negative regulator of BMP signaling for Smad6. NPM1 is an

Table 1 | Cell cycle progression of MC3T3 cells treated with PMNT for different time (\%)

\begin{tabular}{|c|c|c|c|c|c|c|c|c|c|c|c|c|}
\hline & \multicolumn{2}{|c|}{$4 \mathrm{~h}$} & \multicolumn{2}{|c|}{$8 \mathrm{~h}$} & \multicolumn{2}{|c|}{$12 \mathrm{~h}$} & \multicolumn{2}{|c|}{$14 \mathrm{~h}$} & \multicolumn{2}{|c|}{$16 \mathrm{~h}$} & \multicolumn{2}{|c|}{$24 \mathrm{~h}$} \\
\hline G1 & 83.34 & 83.70 & 71.25 & 67.75 & 71.84 & 59.64 & 68.26 & 55.65 & 65.45 & 62.80 & 71.25 & 75.32 \\
\hline$S$ & 16.66 & 16.30 & 26.14 & 30.66 & 21.90 & 35.18 & 21.54 & 24.26 & 18.82 & 18.13 & 15.96 & 14.12 \\
\hline
\end{tabular}



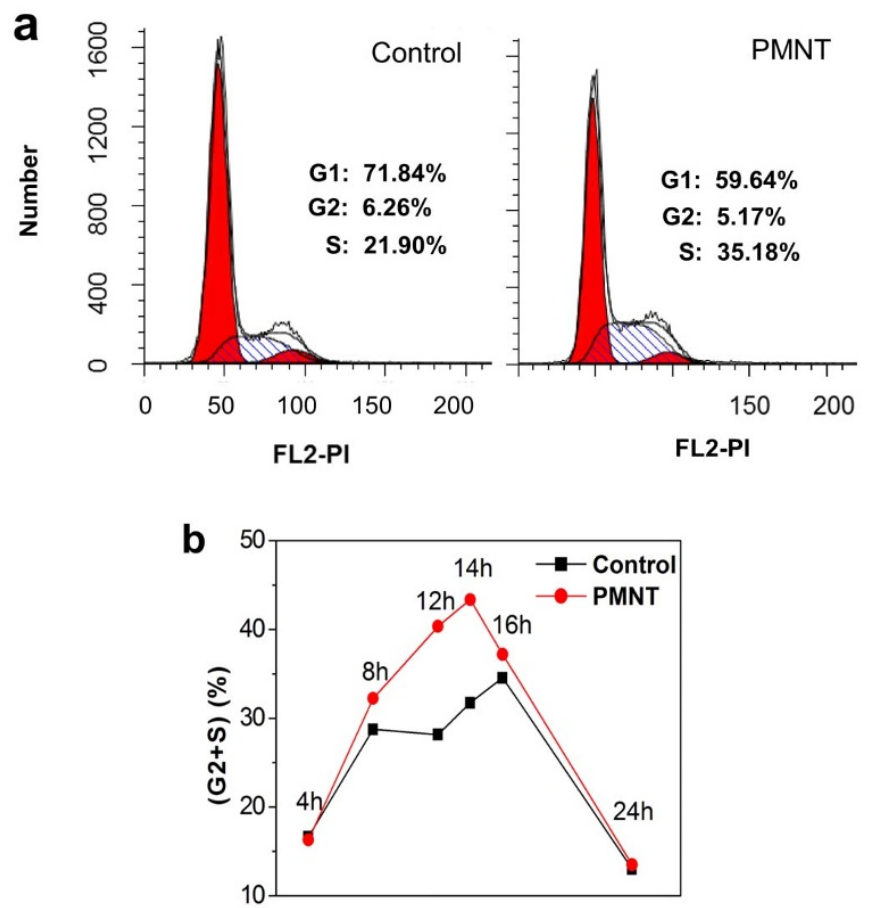

Figure $5 \mid$ (a) Typical flow cytometric analysis for cell cycle distribution of MC3T3 cells treated with or without PMNT at $12 \mathrm{~h}$. (b) The proportion of cells in the $(S+G 2 / M)$ phase as a function of incubation times with PMNT. $[\mathrm{PMNT}]=20 \mu \mathrm{M}$ in RUs.

abundant and ubiquitously expressed phosphoprotein that plays important roles in the regulation of multiple cellular functions ${ }^{26}$. Fibroblast growth factor 7 (FGF7), a member of the FGF family, is involved in a variety of biological processes and FGF7 over expression could enhance cell proliferation ${ }^{27}$. In the result of the cDNA microarray, both NPM1 and FGF7 are significantly up-regulated by PMNT with the Cy5/Cy3 ratios of 3.96 and 4.28 , respectively. GADD45g is a cell cycle protein that plays a key role in cell differentiation and negative control of cell growth ${ }^{28}$. During the cell mitosis, GADD45g can inhibit cell proliferation at different stages, including G1-S and G2-M checkpoints ${ }^{29}$. Our study shows that GADD45g is down regulated by PMNT with the Cy5/Cy3 ratio of 0.25 . Therefore, the growth promotion of PMNT may be closely related to its gene regulation in signaling pathways.

\section{Methods}

Materials. All the reagents and solvents used were commercially available. Fetal bovine serum (FBS) was purchased from Sijiqing Biological Engineering Materials (Hangzhou, China). MTT was obtained from Xinjingke Biotech (Beijing, China) and dissolved in $1 \times$ PBS before use. Primary mouse osteoblasts cell (MC3T3) was purchased from Cell Culture Center of Institute of Basic Medical Sciences, Chinese Academy of Medical Sciences (Beijing, China) and cultured in $\alpha$-MEM supplemented with $10 \%$ FBS. The water was purified using a Millipore filtration system. PMNT were prepared according to the procedures in the literature ${ }^{18}$.

Measurements. Phase contrast bright-field images were taken with fluorescence microscope (Olympus I $\times 71)$ with a mercury lamp $(100 \mathrm{~W})$ as light source. The absorbance for MTT analysis was recorded on a microplate reader (BIO-TEK Synergy $\mathrm{HT}$ ) at a wavelength of $520 \mathrm{~nm}$. Confocal laser scanning microscopy (CLSM) characterization was conducted by a confocal laser scanning biological microscope (FV1000-IX81, Olympus). Flow cytometric analysis was taken by flow cytometry (FACS Calibur, BD).

Assay for cell viability. MC3T3 cells were routinely grown in $\alpha$-MEM medium containing $10 \% \mathrm{FBS}$ in a humidified atmosphere containing $5 \% \mathrm{CO}_{2}$ at $37^{\circ} \mathrm{C}$ and then harvested for subculture using trypsin $(0.05 \%$, Gibco/Invitrogen). Cells were subcultured in 96-well plates the day before the experiment at a density of $4 \sim 7 \times 10^{4}$ cells $\mathrm{mL}^{-1}$. Varying PMNT concentrations were respectively added into the cells followed by further culture for $48 \mathrm{~h}$, then the culture media were discarded and MTT $\left(1 \mathrm{mg} \mathrm{mL}{ }^{-1}, 100 \mu \mathrm{L}\right.$ per well) was added to the wells followed by incubation at $37^{\circ} \mathrm{C}$
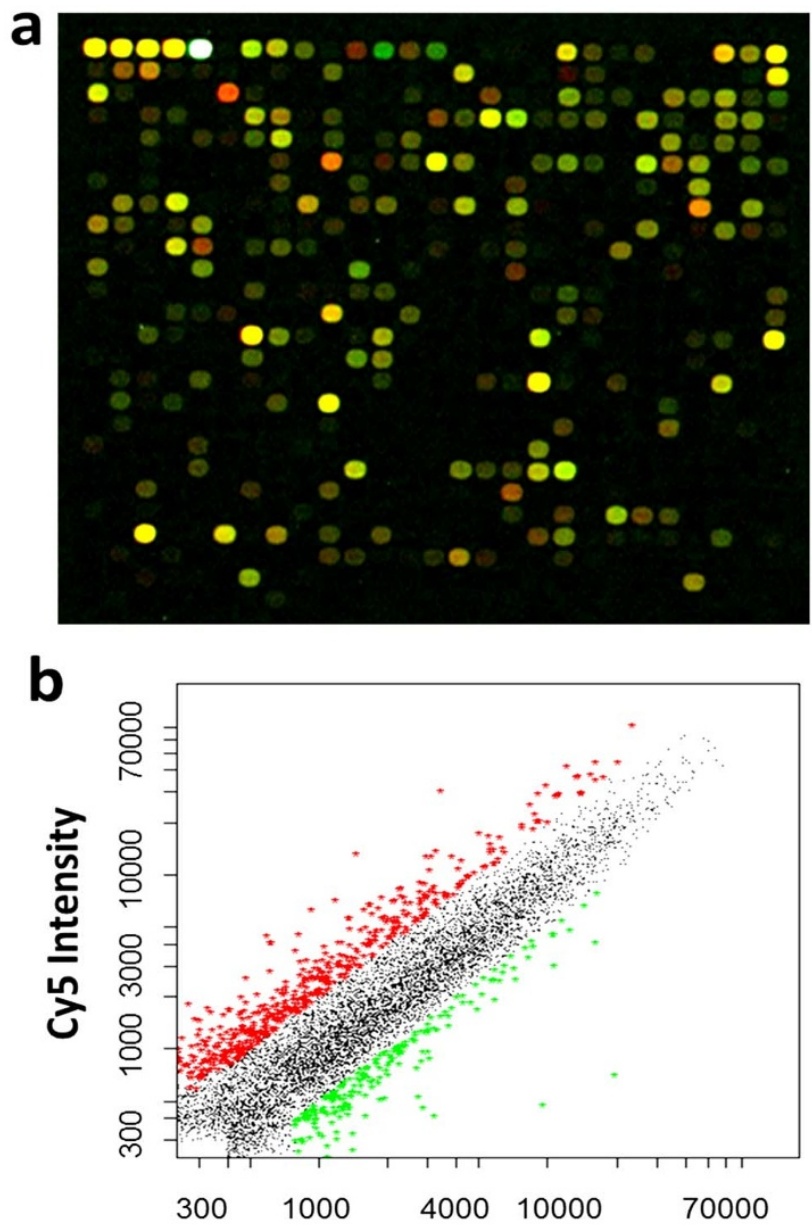

Cy3 Intensity

Figure 6 | (a) A typical merged microarray hybridization image of $\mathrm{Cy} 3$ (control sample) and Cy5 (PMNT-treated sample). (b) PMNT-regulated changes in gene expression. The Cy3 signal is shown on the $\mathrm{x}$ axis and the Cy5 signal is shown on the $y$ axis. The red color stands for the up-regulated genes with the $\mathrm{Cy} 5 / \mathrm{Cy} 3$ ratio $\geq 2.0$; the green color stands for the downregulated genes with the $\mathrm{Cy} 5 / \mathrm{Cy} 3$ ratio $\leq 0.5$; the color black stands for the genes normally expressed. PMNT induces a progressively larger alteration of gene expression.

for $4 \mathrm{~h}$. The supernatant was abandoned and added $150 \mu \mathrm{L}$ DMSO per well was added to dissolve the produced formazan and the plates were shaken for an additional $10 \mathrm{~min}$. The absorbance values of the wells were then read with microplate reader at a wavelength of $520 \mathrm{~nm}$ (Synergy HT, Bio-Tek). The cell viability rate (VR) was calculated according to the following equation, where the control group was carried out in the absence of the drugs.

$$
\operatorname{VR}(\%)=A_{\text {experimental group }} / A_{\text {control group }} \times 100 \%
$$

Confocal laser scanning microscopy (CLSM) measurements. MC3T3 cells were seeded onto $35 \mathrm{~mm}$ Petri dishes with glass bottoms and allowed to incubate for $24 \mathrm{~h}$ for attachment, and then cells were treated in $\alpha$-MEM medium containing PMNT $(20 \mu \mathrm{M})$ but without serum for $12 \mathrm{~h}$. The medium was removed and the cells were washed with phosphate buffered saline $(1 \times \mathrm{PBS}, \mathrm{pH} 7.4)$ for three times. After fixation with $4 \%$ formaldehyde for $15 \mathrm{~min}$, the fixation solution was abandoned and the cells were washed with $1 \times$ PBS for three times. Then the cells were stained by Hoechst 33258 (nuclear dye, $0.5 \mu \mathrm{g} / \mathrm{mL}$ ) for $20 \mathrm{~min}$. After the staining solution was removed and the cells were washed with $1 \times$ PBS for three times, the cells were examined by confocal laser scanning microscopy (FV1000-IX81, Olympus) using a $405 \mathrm{~nm}$ laser for Hoechst 33258 and $488 \mathrm{~nm}$ laser for PMNT. The fluorescence of PMNT was highlighted in yellow and nuclear dye in blue.

Analysis of MC3T3 cells growth promotion by PMNT. The MC3T3 cells were seeded in $35 \mathrm{~mm}$ culture plates (Nunc) at a density of approximately $8 \times 10^{4}$ cells per plate for $12 \mathrm{~h}$, the medium was removed and the cells were washed with $1 \times$ PBS 


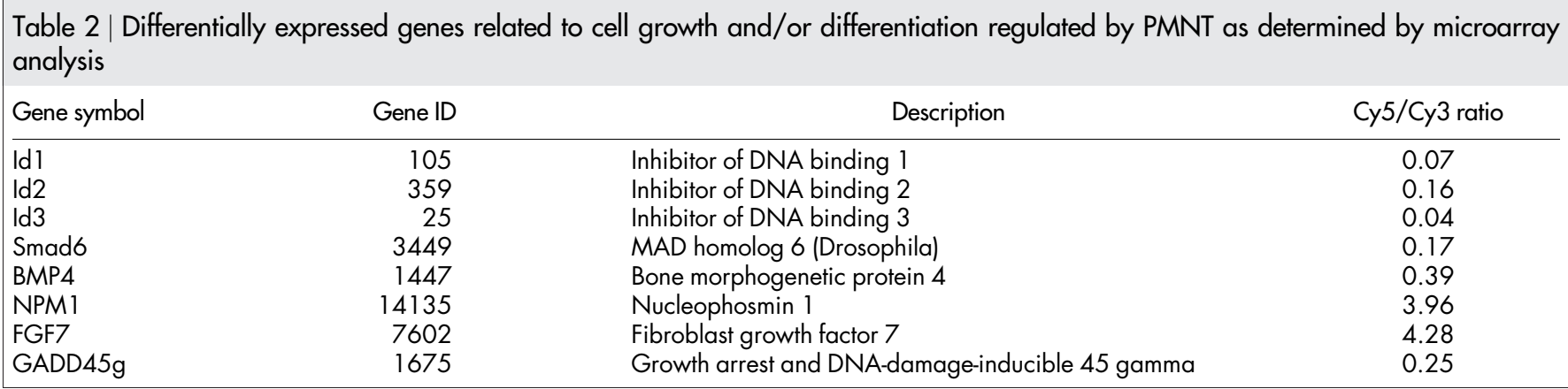

once. The cells were then cultured in $1 \mathrm{~mL} \alpha$-MEM medium containing PMNT $(20 \mu \mathrm{M})$ without serum. The cells cultured in $1 \mathrm{~mL} \alpha$-MEM medium without serum and PMNT as controls. Phase contrast images were taken at different hours $(0-72 \mathrm{~h})$ using fluorescence microscopy (IX71, Olympus). The cells for number count at different hours $(0-72 \mathrm{~h})$ were harvested using trypsin and collected in $1 \mathrm{~mL}$ culture medium.

Cell cycle analysis by flow cytometry. The MC3T3 cells were seeded in $35 \mathrm{~mm}$ culture plates (Nunc) for $12 \mathrm{~h}$, the medium was removed and the fresh medium without serum was added for another 12 h. $\alpha$-MEM medium containing PMNT $(20 \mu \mathrm{M})$ was added into the cells followed by further culture for different hours $(4-24 \mathrm{~h})$. The cells at a density of approximately $10^{6}$ cells per plate were harvested using trypsin and collected in PBS. The PBS solution of cells was then fixed by $70 \%$ ethanol at $4{ }^{\circ} \mathrm{C}$ for over $18 \mathrm{~h}$. Centrifuge the ethanol-suspended cells and decant ethanol thoroughly. Suspend the cell pellet in PBS, RNase $(100 \mu \mathrm{g} / \mathrm{mL})$ was added and the cells were kept in dark at $37^{\circ} \mathrm{C}$ for $30 \mathrm{~min}$. Centrifuge the suspended cells and decant RNase. Suspend the cell pellet in $1 \mathrm{~mL}$ of PI $(25 \mu \mathrm{g} / \mathrm{mL})$ staining solution. Keep in the dark at $4^{\circ} \mathrm{C}$ for $1 \mathrm{~h}$. The pre-prepared cell suspensions were directly analyzed using flow cytometry (FACS Calibur, BD). Cell fragments were excluded with forward and side-scatter gating to ensure that all detected signals originated from relatively intact cells; signals PI were individually recorded in Channel FL-1. The flow cytometry diagrams presented were obtained from a population of $3 \times 10^{4}$ cells.

cDNA microarray analysis. 1) Cell culture and treatment. The MC3T3 cells were seeded in $35 \mathrm{~mm}$ culture plates (Nunc) for $12 \mathrm{~h}$, the medium was removed and the medium without serum was added for another $12 \mathrm{~h}$. $\alpha$-MEM medium containing PMNT $(20 \mu \mathrm{M})$ was added into the cells followed by further culture for $12 \mathrm{~h}$. Untreated cells were used as reference samples and referred to as controls in the analyses.

2) RNA sample preparation. MC3T3 cells were lysed and homogenized in Trizol reagent (Invitrogen), and total RNA was prepared according to the manufacturer's instructions.

3) cDNA microarray hybridization. CapitalBio $32 \mathrm{k}$ Mouse Genome Array contains 32256 genes of known and unknown function (CapitalBio, Beijing, China). The reference RNA samples from MC3T3 cells were labeled with Cy3, and the test RNA samples from MC3T3 cells treated with PMNT $(20 \mu \mathrm{M})$ for 12 hours were labeled with Cy5. The Cy3-labeled and Cy5-labeled samples were hybridized simultaneously to the same array.

4) Microarray analysis. Arrays were scanned with a confocal LuxScan ${ }^{\mathrm{TM}}$ scanner and the images obtained were then analyzed using LuxScan ${ }^{\mathrm{TM}} 3.0$ software (Both from

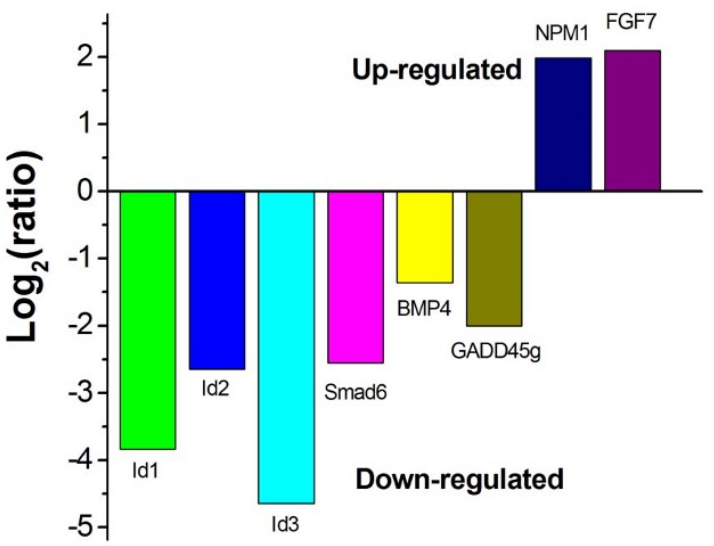

Figure $7 \mid$ The relative value of the gene expression level for the PMNTtreated group compared to that of the control group.
CapitalBio). $\mathrm{Cy} 5 / \mathrm{Cy} 3$ ratio represents the relative abundance of a target transcript in PMNT-treated and nontreated samples respectively. A signal to control channel ratio $>2.0$ was defined as upregulation by PMNT. A signal to control channel ratio $<0.4$ was defined as downregulation. To determine the significant differentially expressed genes, Significance Analysis of Microarrays (SAM, version 3.02) were performed.

1. Flores, I., Cayuela, M. L. \& Blasco, M. A. Effects of telomerase and telomere length on epidermal stem cell behavior. Science 309, 1253-1256 (2005).

2. Levenberg, S. et al. Differentiation of human embryonic stem cells on threedimensional polymer scaffolds. Proc. Natl. Acad. Sci. USA 100, 12741-12746 (2003).

3. Molofsky, A. V. et al. Bmi-1 dependence distinguishes neural stem cell selfrenewal from progenitor proliferation. Nature 425, 962-967 (2003).

4. van der Valk, J. et al. Optimization of chemically defined cell culture media Replacing fetal bovine serum in mammalian in vitro methods. Toxicol. in Vitro 24, 1053-1063 (2010).

5. Toriniwa, H. \& Komiya, T. Comparison of viral glycosylation using lectin blotting with Vero cell-derived and mouse brain-derived Japanese encephalitis vaccines. Vaccine 29, 1859-1862 (2011).

6. Iwata, K. et al. The development of a serum-free medium utilizing the interaction between growth factors and biomaterials. Biomaterials 33, 444-454 (2012).

7. Liu, G. et al. Optimal combination of soluble factors for tissue engineering of permanent cartilage from cultured human chondrocytes. J. Biol. Chem. 282, 20407-20415 (2007).

8. Takahashi, T. et al. Synergistic effects of FGF-2 with insulin or IGF-I on the proliferation of human auricular chondrocytes. Cell Transplant. 14, 683-693 (2005).

9. Choi, Y. \& Nam, T.-G. Chemical biology in stem cell research. Arch. Pharmacal Res. 35, 281-297 (2012).

10. Firestone, A. J. \& Chen, J. K. Controlling destiny through chemistry: smallmolecule regulators of cell fate. ACS Chem. Biol. 5, 15-34 (2010).

11. Xu, Y., Shi, Y. \& Ding, S. A chemical approach to stem-cell biology and regenerative medicine. Nature 453, 338-344 (2008).

12. Shen, G. et al. A 2,6-Disubstituted 4-anilinoquinazoline derivative facilitates cardiomyogenesis of embryonic stem cells. ChemMedChem 7, 733-740 (2012).

13. Ghasemi-Mobarakeh, L. et al. Application of conductive polymers, scaffolds and electrical stimulation for nerve tissue engineering. J. Tissue Eng. Regen. Med. 5, e17-e35 (2011)

14. Mawad, D. et al. A single component conducting polymer hydrogel as a scaffold for tissue engineering. Adv. Funct. Mater. 22, 2692-2699 (2012).

15. Smela, E. Conjugated polymer actuators for biomedical applications. Adv. Mater. 15, 481-494 (2003).

16. Liu, Y., Liu, X., Chen, J., Gilmore, K. J. \& Wallace, G. G. 3D Bio-nanofibrous PPy/ SIBS mats as platforms for cell culturing. Chem. Commun. 44, 3729-2731 (2008).

17. Quigley, A. F. et al. A conducting-polymer platform with biodegradable fibers for stimulation and guidance of axonal growth. Adv. Mater. 21, 4393-4397 (2009).

18. Ho, H.-A. et al. Colorimetric and fluorometric detection of nucleic acids using cationic polythiophene derivatives. Angew. Chem. Int. Ed. 41, 1548-1551 (2002).

19. Duan, X., Liu, L., Feng, F. \& Wang, S. Cationic conjugated polymers for optical detection of DNA methylation lesions and single nucleotide polymorphisms. Acc. Chem. Res. 43, 260-270 (2010).

20. Liu, L., Yu, M., Duan, X. \& Wang, S. Conjugated polymers as multifunctional biomedical platforms: anticancer activity and apoptosis imaging. J. Mater. Chem. 20, 6942-6947 (2010).

21. Yang, G., Liu, L., Yang, Q., Lv, F. \& Wang, S. A multifunctional cationic pentathiophene: synthesis organelle-selective imaging and anticancer activity. Adv. Funct. Mater. 22, 736-743 (2012).

22. Xing, C., Xu, Q., Tang, H., Liu, L. \& Wang, S. Conjugated polymer/porphyrin complexes for efficient energy transfer and improving light-activated antibacterial activity. J. Am. Chem. Soc. 131, 13117-13124 (2009).

23. Benezra, R., Davis, R. L., Lockshon, D., Turner, D. L. \& Weintraub, H. The protein Id: a negative regulator of helix-loop-helix DNA binding proteins. Cell 61, 49-59 (1990). 
24. King, K. E., Iyemere, V. P., Weissberg, P. L. \& Shanahan, C. M. Kruppel-like factor 4 (KLF4/GKLF) is a target of bone morphogenetic proteins and transforming growth factor beta 1 in the regulation of vascular smooth muscle cell phenotype. J. Biol. Chem. 278, 11661-11669 (2003).

25. Imamura, T. et al. Smad6 inhibits signalling by the TGF- $\beta$ superfamily. Nature 389, 622-626 (1997).

26. Liu, W. H. \& Yung, B. Mortalization of human promyelocytic leukemia HL-60 cells to be more susceptible to sodium butyrate-induced apoptosis and inhibition of telomerase activity by down-regulation of nucleophosmin/B23. Oncogene 17, 3055-3064 (1998).

27. Vainio, S. \& Lin, Y. Coordinating early kidney development: lessons from gene targeting. Nat. Rev. Genet. 3, 533-543(2002).

28. McLean, C. Y. et al. Human-specific loss of regulatory DNA and the evolution of human-specific traits. Nature 471, 216-219(2011)

29. Vairapandi, M., Balliet, A. G., Hoffman, B. \& Liebermann, D. A. GADD45b and GADD 45g are $\mathrm{cdc} 2 / \mathrm{cyclinB} 1$ kinase inhibitors with a role in $\mathrm{S}$ and G2/M cell cycle checkpoints induced by genotoxic stress. J. Cell. Physiol. 192, 327-338 (2002).

\section{Acknowledgments}

This work was supported by the National Natural Science Foundation of China (Nos. 21033010, 21003140, 21021091) and the Major Research Plan of China (Nos. 2011CB808400, 2013CB932800, 2011CB935800).

\section{Author contributions}

M.G. and L.L. designed and performed experiments, analysed data and wrote the manuscript. F.L. analysed data. S.W. designed experiments, analysed data and wrote the manuscript.

\section{Additional information}

Competing financial interests: The authors declare no competing financial interests.

License: This work is licensed under a Creative Commons

Attribution-NonCommercial-NoDerivs 3.0 Unported License. To view a copy of this license, visit http://creativecommons.org/licenses/by-nc-nd/3.0/

How to cite this article: Yang, G., Liu, L., Lv, F. \& Wang, S. Conjugated Polyelectrolyte Materials for Promoting Progenitor Cell Growth Without Serum. Sci. Rep. 3, 1702; DOI:10.1038/srep01702 (2013) 